\title{
Nutritional Evaluation of Brachiaria brizantha cv. marandu using Convolutional Neural Networks
}

\author{
Bruno Rover Dal Prá[ ${ }^{\left.1,2,{ }^{*}\right]}$, Roberto Navarro de Mesquita $^{[1]}$, Mário Olímpio de Menezes ${ }^{[1]}$, \\ Delvonei Alves de Andrade ${ }^{[1]}$ \\ ${ }^{[1]}$ Energy and Nuclear Research Institute - IPEN, São Paulo, São Paulo 05508-000, Brazil \\ ${ }^{[2]}$ Federal Institute of Rondônia - IFRO-VHA, Vilhena, Rondônia 76982-270, Brazil \\ ${ }^{[*]}$ Corresponding Author: bruno.dalpra@ifro.edu.br
}

\begin{abstract}
The identification of plant nutritional stress based on visual symptoms is predominantly done manually and is performed by trained specialists to identify such anomalies. In addition, this process tends to be very time consuming, has a variability between crop areas and is often required for analysis at various points of the property. This work proposes an image recognition system that analyzes the nutritional status of the plant to help solve these problems. The methodology uses deep learning that automates the process of identifying and classifying nutritional stress of Brachiaria brizantha cv. marandu. An image recognition system was built and analyzes the nutritional status of the plant using the digital images of its leaves. The system identifies and classifies Nitrogen and Potassium deficiencies. Upon receiving the image of the pasture leaf, after a classification performed by a convolutional neural network $(\mathrm{CNN})$, the system presents the result of the diagnosed nutritional status. Tests performed to identify the nutritional status of the leaves presented an accuracy of $96 \%$. We are working to expand the data of the image database to obtain an increase in the accuracy levels, aiming at the training with a larger amount of information presented to $\mathrm{CNN}$ and, thus, obtaining results that are more expressive.
\end{abstract}

Keywords: Machine learning, Computer Vision, Plant Nutrition, Convolutional Neural Network.

Resumen La identificación del estrés nutricional de las plantas en función de los síntomas visuales, se realiza predominantemente de forma manual y es realizada por especialistas capacitados para poder identificar tales anomalías. Además, este proceso tiende a consumir mucho tiempo y tiene variabilidad entre las áreas de cultivo, la mayoría de las veces requiere un análisis en varios puntos de la propiedad. Este trabajo propone un sistema de reconocimiento de imágenes que analiza el estado nutricional de la planta para contribuir a la solución de estos problemas. La metodología utiliza el aprendizaje profundo que automatiza el proceso de identificación y clasificación del estrés nutricional de Brachiaria brizantha cv. marandu Se construyó un sistema de reconocimiento de imágenes que analiza el estado nutricional de la planta utilizando imágenes digitales de sus hojas. El sistema identifica y clasifica las deficiencias de nitrógeno y potasio, además de identificar si la planta está sana. Al recibir la imagen de la hoja del pasto, luego de una clasificación realizada por una red neuronal convolucional (CNN), el sistema presenta el resultado del estado nutricional diagnosticado. Las pruebas realizadas para identificar el estado nutricional de las hojas mostraron una precisión del $96 \%$ en la prueba. Estamos trabajando para expandir la base de datos de la base de datos de imágenes para obtener un aumento en los niveles de precisión, lo que permite llevar a cabo una capacitación con una mayor cantidad de información presentada a CNN y, por lo tanto, obtener resultados más expresivos

\section{Introduction}

Brazil is currently home to the largest commercial beef herd in the world, it is also the world's largest exporter of beef in tons and turnover. Livestock occupies approximately 220 million hectares, 70 million in the Amazon alone [1]. 
Virtually all Brazilian beef production is based on pastures, the most economical and practical way of producing and offering food for cattle. Pastures, therefore, play a fundamental role in Brazilian livestock, guaranteeing low production costs [2].

Considering this data, grass degradation is one of the biggest problems faced today by Brazilian breeders [3].

Livestock in the Amazon region still has a low technological level, despite recent advances. Therefore, investments in innovations to improve production rates are a fundamental issue for the sustainable development of the region [1].

The state of Rondônia exported, in 2012, 208.2 thousand tons of beef and 35.3 thousand tons of giblets to 31 countries, totaling R 2.5 billion. Its participation constitutes a $20 \%$ slice of all beef exported by Brazil. The expectation for the upcoming years is for growth in exports and, consequently, an increase in the number of animals and pastures being cultivated, requiring better control to obtain better productivity numbers [4]. Which consists in improving the food quality for the cattle, since an animal with good genetics will only express its production potential if it is properly fed [5].

Brachiaria brizantha is a cultivar that was introduced in Brazil in 1952, but is originally from South Africa. The option for its cultivation in the country is justified by the fact that it is considered an excellent forage, perennial and with great production of good quality leaf mass, resistant to grazing and trampling and it protects the soil against erosion [5,6]. Brachiaria grasses occupy more and more space in Brazilian livestock. After its implantation and, as it demands little from rich soils, Brachiaria is configured as an essential food in cattle breeding, both beef and dairy. As pastures continue to be treated as extractive and widely used crops in Brazil, no necessary attention is paid to the management and correction of soil fertility [7]. In addition to the inexistence of this correction, since it is a crop where replanting is not performed annually, it is necessary to maintain soil fertility and consequently its productivity.

Until recently, pastures were not considered crops and did not receive proper care concerning nutritional status and management. This resulted in immense areas of degraded pastures and created a major national problem since most of these pastures occupy arable land [8].

The soil is the means from which plants, through root absorption, obtain essential mineral elements. When the medium does not have and or does not provide adequate amounts of nutrients, which has been assessed by chemical analysis of the soil, plants will not have their nutritional requirements met. Therefore, there will be a reduction in crop growth and production due to nutritional deficiency [9].

Diagnosis of the nutritional status of plants can be performed visually since the lack or excess of a given element always causes the same manifestation of abnormality visible in any species [10].

The leaves reflect well the level of soil elements. A chemical analysis of the soil can be replaced by an analysis of the leaf, so a soil sample can be replaced by a leaf sample [11].

A way to assess soil fertility is by performing a leaf analysis that, through the characteristics of its leaves, can verify soil deficiencies. Leaf analysis in Brazil began to be carried out at the end of the 19th century at the Agronomical Institute of Campinas (Instituto Agronômico de Campina) (SP) [12].

Plants' mineral nutrients are divided into macronutrients and micronutrients according to the quantities in which they are found in the soil, [13]. Macronutrients are those with a high concentration in the soil and, thus, have a great influence on productivity.

The most limiting minerals are nitrogen $(\mathrm{N})$, potassium $(\mathrm{K})$ and phosphorus $(\mathrm{P})$, which are identified in pastures with a high degree of degradation. These three elements become major production limiters, due to the low levels of organic matter in the soil [14].

The methods currently used to identify possible nutritional deficiencies in plants are visual diagnosis and leaf diagnosis. Both methods are subject to misinterpretation [15]. To minimize possible errors of interpretation and create a tool that efficiently analyzes this data, there are computational methods that perform pattern recognition and image analysis that can be applied to this problem. One is the use of deep learning, which is increasingly becoming one of the most important technologies for image classification [16,17]. This methodology consists of developing a computational model inspired by the nervous system of living beings, where the idea of neurons is used to simulate the human brain [18].

Several studies have been carried out using deep learning applied to image recognition of pathologies in plants; the most promising ones use the architecture of convolutional neural networks (CNN). To identify diseases on leaves, some authors have recently proposed the use of CNN to perform the identification of diseases through digital images extracted from leaves [16,19-26].

CNN's were also used to identify shapes in images, being applied to identify the size and quality of barley grains [27] and also in the detection and counting of plant organs in grape cultivation [28]. 
Tran et al. (2019) implemented CNN models to identify the deficiency of the macronutrients Calcium, Nitrogen and Potassium. In his study, he obtained results with $87.27 \%$ of accuracy, using a convolutional neural network known as Inception-ResNet (Deep Residual Neural Network). Ghosal et al. (2018) besides carrying out analyzes of two nutritional deficiencies using CNNs, he was also able to diagnose five pathologies present in the leaves in the same network, obtaining an excellent performance reaching a total accuracy of $94.13 \%$.

In this study, we propose the use of a new method to assess the nutritional status of Nitrogen, potassium and healthy plant for pastures of the Brachiaria brizantha cv. marandu, utilizing a technology based on deep convolutional neural networks (CNN). For the implementation of the system, it was necessary to create a database leaves images of the cultivar inducing the deficiencies, totalling 249 images between healthy and unhealthy. From the set of images, $80 \%$ were used for system training and $20 \%$ applied to tests [29]. The CNN was implemented with a five-tiered convolutional and three-tiered architecture, reaching an average accuracy of $96 \%$ on tests.

\section{Materials and methods}

\subsection{System overview}

For the creation of a supervised deep learning system, Brachiaria brizantha was grown in a greenhouse, where nitrogen and potassium deficiencies were induced, in addition to a full dose of nutrients, to allow the visualization of nutritional characteristics, both for deficiencies and healthy plants.

The images of the leaves were captured with a cell phone digital camera with Full HD resolution, described in detail in item 2.4 of this work, and, thus, making it possible to create the system's database.

In the proposed system, the concept of leaf analysis was used, which uses the images of leaves to diagnose the nutritional status. Thus, these leaves were collected and catalogued in the form of digital images to create the knowledge base, enabling supervised training of the intelligent system. Besides, the image database was expanded using the Data Augmentation technique and other preprocessing so that the images would stay with the most relevant standard for faster and more accurate training, achieving better results. This also allows photos of the leaves at various angles and different brightness levels and contrast while maintaining acceptable levels of performance [30].

\subsection{Dataset creation}

For the development of the research, a dataset (Database) was created, which served as a knowledge base. As previously said, the system is of the supervised type, that is, it needs data to enable training related to artificial intelligence. After training, the system can perform the recognition of nutritional deficiencies through the images of the plants.

The visual deficiency symptoms characterized were: Nitrogen and Potassium in the culture of Brachiaria brizantha cv. marandu, grown in a greenhouse, which was weekly recorded in photos of each experimental unit. Samples were also grown with a complete level of nutrients, so that, the system, in addition to assessing deficiencies, could also identify healthy plants.

With the data initially classified, compared and catalogued it was possible to obtain the correlation between the levels of nutrient deficiency and the images.

\subsection{Cultivation of samples}

The samples were grown in a greenhouse and the experimental design was in randomized blocks, arranged in a $3 \times 3$ factorial scheme, with three nutrients ( $\mathrm{N}, \mathrm{K}$ and Complete) and three levels of fertilization, namely: initial level of the substrate itself, $50 \%$ and $100 \%$ of the recommended doses for the culture. The

evaluations were carried out with five repetitions, totalling 45 experimental units. The experimental unit consisted of pots with a capacity of 20 litres, which were filled with sandy soil of low natural fertility, with the addition of nutrients for each treatment as shown in Figure 1 and Figure 2.

For fertilization, a nutrient solution of macronutrients was prepared, composed of the commercial products urea at a concentration of $21.7 \mathrm{~g} / 1$ (nitrogen source), Triple Superphosphate at a concentration of $37.11 \mathrm{~g} / 1$ (phosphorus source) and Potassium Chloride in concentration of $16.3 \mathrm{~g} / 1$ (potassium source), $5 \mathrm{ml}$ is recommended for $1 \mathrm{~kg}$ of soil. The solution was prepared in the laboratory individually for each macronutrient and applied according to the treatments.

The amount of sand was the same for all pots and irrigation was performed on alternate days using an amount of water that would be the "pot" capacity, with the value calculated using $80 \%$ of the field capacity[31].

The images were taken in the middle third of the plant, using three to four diagnostic leaves per pot and recorded weekly as described in table 1 . 
Table 1 - Planting period and image registration.

\begin{tabular}{lcc}
\multicolumn{1}{c}{ Stage } & Day & Evaluation and photography \\
\hline Planting & $08 / 01 / 2019$ & No \\
First evaluation & $16 / 02 / 2019$ & Yes \\
Second evaluation & $22 / 02 / 2019$ & Yes \\
Third evaluation & $15 / 03 / 2019$ & Yes \\
Cutting & $19 / 03 / 2019$ & No \\
Fourth evaluation & $07 / 06 / 2019$ & Yes \\
Fifth evaluation & $15 / 06 / 2019$ & Yes \\
Sixth evaluation & $21 / 06 / 2019$ & Yes \\
\hline
\end{tabular}

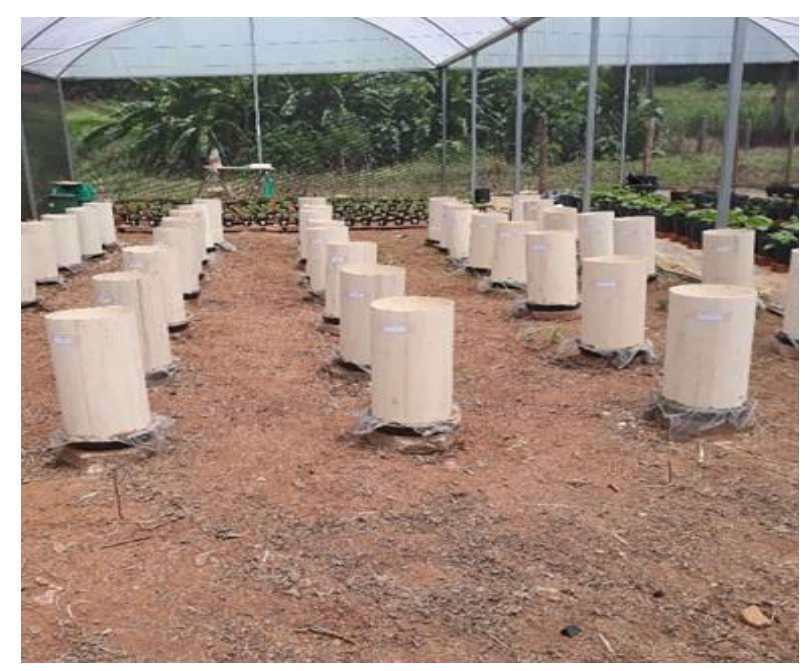

Figure 1 - Experimental area.

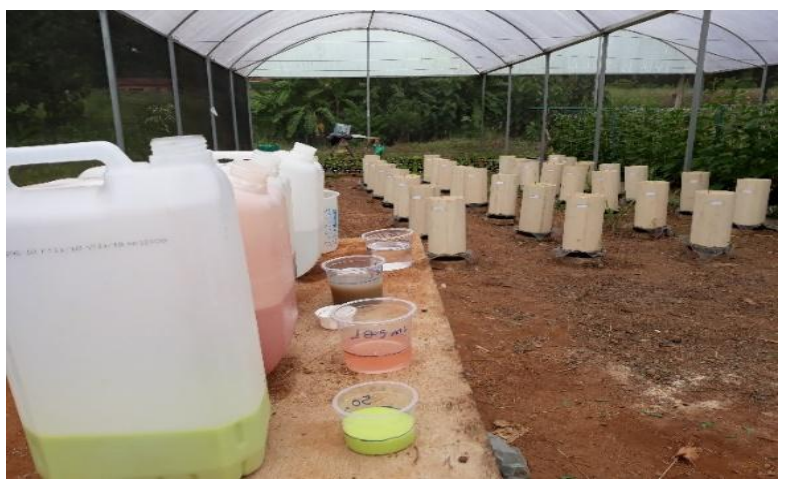

Figure 2 - Fertilization of the respective treatments.

\subsection{Image acquisition}

The images were captured with a Samsung Galaxy J7 Pro cell phone that has a 13 MP camera, f/1.9, LED flash, $1080 \mathrm{p}$ and Foto Still Photo Studio with a $60 \times 60 \mathrm{~cm}$ Tent with the illumination of two neutral colour led plates $(5500 \mathrm{k})$ and $30 \mathrm{~W}$ of power each.

The photographs had a framed view of the plant + pot, aerial part and diagnostic leaf focusing from the tip to the base of the leaf.

In figure 3, the leaves are classified as potassium deficient leaf (image A) at the substrate level, as well as nitrogen deficient (image B) at the substrate level and with complete nutrition (image C).

In these images, it can be seen that the characteristics of the deficiencies are visible. Nitrogen deficiency manifesting itself in the yellowish leaf in the shape of a "V" and the potassium deficiency in the necrosis of the leaf edges. 
In the experiments, 45 images of the pasture with complete fertilization, 100 images with potassium deficiency $(\mathrm{K})$ and 104 images with nitrogen deficiency $(\mathrm{N})$ were generated (exemple in figure 3), totalling 249 images in the dataset. They were used to feed the system and thus teach our model to identify the nutritional status.

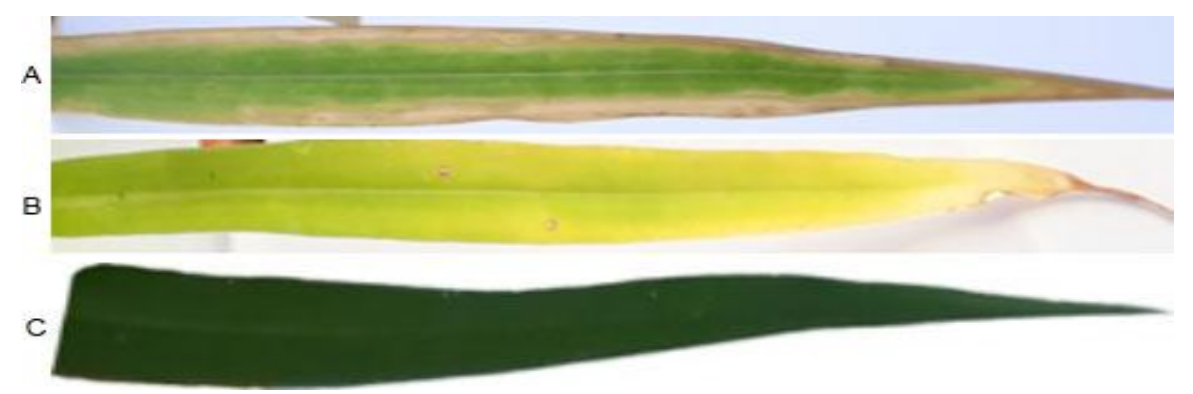

Figure 3 - Image with potassium (A), nitrogen (B) deficiency at the substrate level and healthy plant (C).

\subsection{Pre-processing of Dataset}

One of the advantages of using CNN - Deep Learning is less need to use resource engineering, thus requiring less use of image processing to extract features, the same being found by the network training itself $[32,33]$ They use the images directly as input data, thus avoiding the extraction of complex characteristics, as in traditional image recognition algorithms [21].

The convolutional neural network received only raw data without any extraction of characteristics, only the pixel matrix as input.

As the technology used is Deep Learning, there is a need for a significant number of images for training with relevant levels of accuracy. This is because as this technology works as an exceptional feature extractor, the greater number of samples, the more characteristics the network can learn, thus improving recognition levels [17,34]. However, we have no way to specify an exact number of samples, this depends on the complexity of the problem in question $[16,17,28]$ To improve the performance of the CNN, reducing overfitting, it is possible to create images artificially using a technique known as Data Augmentation [35-37].

This approach uses image processing techniques to increase the number of images in the dataset, making position shifting, rotating image objects, as well as changing brightness, dilation and erosion of edges and contrast of images $[23,26,38]$. The input set was increased by 8 times by mirroring and rotating the images, thus generating a total of 1992 samples[16], described in table 2 and figure 4.

The images were classified and labelled in 3 distinct classes, each label represents a nutritional status of the plant, being healthy class, nitrogen deficiency class, potassium deficiency class. In item 2.4, an example of each nutritional status assessed can be seen.

To carry out the training, the network requires that all images have the same dimensions, for that reason the images used have been resized with dimensions $300 \times 300$ pixels [39].
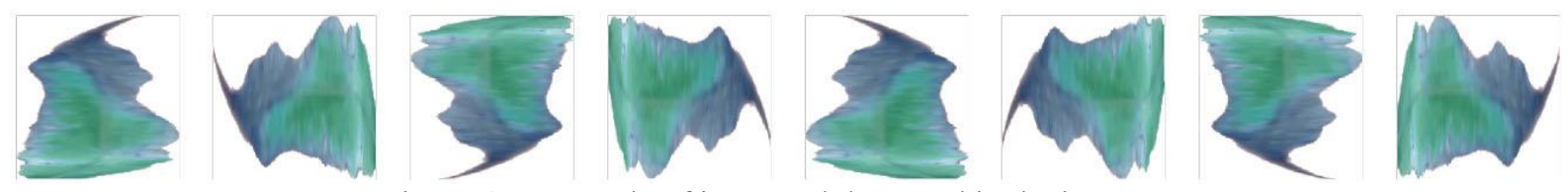

Figure 4 - Example of increased data used in the images. 
Table 2 - List of nutrients and number of samples after Data Augmentation.

\begin{tabular}{lcc} 
Nutrients & Number of samples & Number of samples after Data Augmentation \\
\hline Potassium deficiency (K) & 100 & 800 \\
Nitrogen deficiency (N) & 104 & 832 \\
Plant with complete nutrition & 45 & 360 \\
Total & 249 & 1992 \\
\hline
\end{tabular}

\subsection{Data Adjustment}

The data adjustment, necessary for the training, was carried out by dividing the pixels by 255 , leaving the pixel values between 0 and 1 [40]. This is necessary for numerical stability in the algorithms and with that, they converge more quickly and become more accurate when their data is normalized in the range 0 to 1 .

That way, the same scale was guaranteed, preventing the algorithm from interpreting the data differently [41].

\subsection{Technology Used}

The training and testing processes of this CNN model were implemented using scikit-learn, Keras, TensorFlow, pillow, numpy, matplotlib, opencv, among other libraries, that use the python programming language. The training and testing of the models were performed using a machine with a Core i5-7400k CPU, 16GB of RAM and an NVIDIA TITAN XP GPU with Pascal architecture, 12GB of memory and with the performance of 12 TFLOPS.

\subsection{Proposed CNN model}

Convolution neural networks (CNN) can be used to create a computational model that uses unstructured inputs and finds outputs with corresponding labels, thereby correlating image inputs with output results [24].

A supervised classification structure was designed and implemented, where $\mathrm{CNN}$ is trained through examples using the images described in item 2.4. CNN's have a great capacity to extract complex characteristics from images, achieving great results in the identification and classification [22]. One of the reasons for choosing such architecture is that the characteristics of nutritional deficiency are very similar to each other, thus, there is a great difficulty for identification, and this model has a great capacity to learn which characteristics are most important enabling the identification of the deficiency that is being analyzed.

The purpose of this CNN is to classify the entrance images as healthy or with nutritional deficiency, if there is a deficiency, indicate which one is between $\mathrm{N}$ and $\mathrm{K}$.

CNN's are made up of input layers that receive the raw pixels of the image, thus the network's input number corresponds to the image size, that is, W (width) $\mathrm{x} \mathrm{H}$ (height) times the colour channel number. In colour images the number of channels is equal to 3 (red, green and blue, for example), so an image 300 pixels wide, 300 pixels tall and with 3 colour channels, would give the CNN a 300x300x3 entry, totalling 270,000 entries [27].

The implemented neural network architecture has 5 convolutional layers (Conv) with 128 filters in each layer, 3 fully connected layers (FC) with 512, 128 and 3 filters respectively, rectified linear function "Relu", pooling layers and dropout, as illustrated in figure. 5

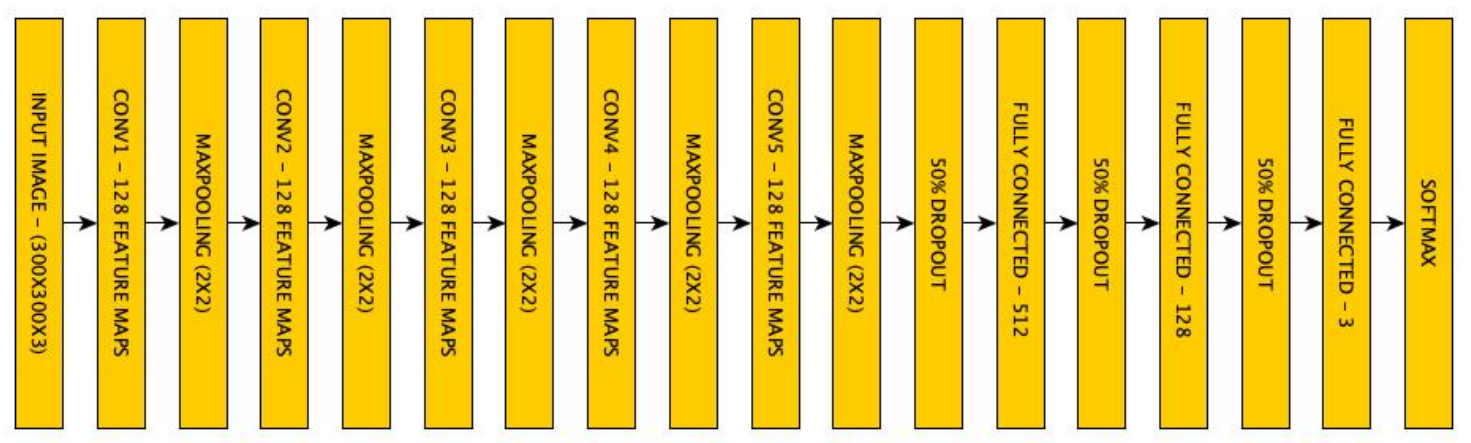

Figure 5 - Layered architecture of the proposed CNN model. 
The various layers of convolution, implemented in this model, generate many representations of data and act as descriptors of characteristics, initially in the first layers with more common information and increasing the detailing of the characteristics as the number of layers deepens [16,22,26,27]

In addition to the convolution layers, we have MaxPooling, which is used to decrease the dimensionality of the image, so that, faster training is possible with a smaller number of parameters [42].

Dropout layers, that have the function of reducing overfitting of the network, were also added to the model by eliminating some neurons in the network by setting them to zero [37].

After the layers mentioned above, there are the fully connected layers - FC, which are responsible for performing the classification using the outputs of the convolution and pooling layers. The last of these layers has 3 outputs. They perform the classification using a softmax function that exponentially normalizes the input received by distributing the values of the 3 classes. It transforms the outputs of each class to values between 0 and 1 and also performs the division by the sum of the exits, thus giving the probability of an entry being in one of the exits [33].

\subsection{Model Training}

To perform the model training the layers' weights were initialized to zero and the network training was performed using the "Adam" optimizer, a variation of the Stochastic Gradient Descent (SGD) technique, an excellent firstorder algorithm for optimization based in gradient of objective stochastic functions, which is based on an adapted estimate of moments of low order [43]. The learning rate was initialized with 0.0001 , lot size 32 , loss function "Categorical Cross-Entropy" and training was performed over 300 periods.

\section{Results and discussions}

The CNN was used to analyze the nutritional status of Brachiaria brizantha cv. marandu, and tests were also carried out to verify efficiency through accuracy. High general classification accuracy of $96 \%$ calculated using Eq. (1), was obtained, showing that the system is behaving very well using an enlarged database. The confusion matrices illustrated in figure. 7 and figure 8 , demonstrate the system's correctness index, showing a great result in the identification of nitrogen deficiency and healthy plant, having a lower level in the case of potassium deficiency, but with an excellent level of effectiveness.

In the accuracy graph in figure 6 (a), we can see that the model's learning has reached a relatively stable level, the test being very close to the training, which shows that our system is learning very well from the training examples and achieving a good generalization.
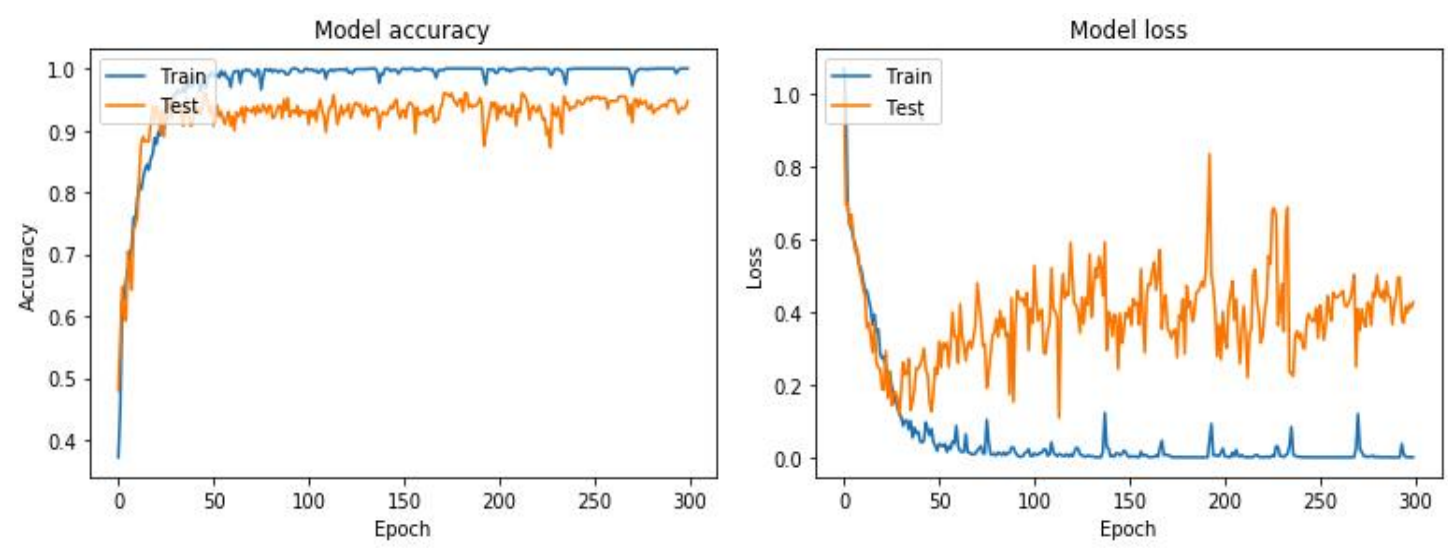

Figure 6 - Accuracy graph (a) and loss graph (b).

If we analyze the loss graph in figure 6 (b) it is possible to see that our model tends to suffer from overfitting, which is the model's over-adjustment, that is, it is learning too much about the data and is not being able to generalize them. One of the ways to solve this problem is to stop training the moment the graph starts to increase the loss values, we saved the best training that was reached in season 46 . This can also occur due to our limited number of samples. 


$$
\text { Acurracy }[\%]=\frac{T P+T N}{T p+F P+T N+F N} \times 100
$$

TP Means True Positive, TN refers to the True Negative value of the image, FP means False Positive and FN signifies False Negative.

System tests were also performed using the database without the use of Augmentation, so the system was trained and tested with a database having an 8 times smaller number of images, totalling 249 images specified in table 2. Using this database the system reached an $88 \%$ level of accuracy.

Therefore, the results of the tests show that creating artificial images using the Augmentation technique is effective for improving the identification of deficiencies in the evaluated crop. It was also confirmed that a larger number of images leads to a better generalization, leading the system to better identify the characteristics of the leaves, with an increase of $8 \%$ in identification, being very significant in identifying the nutritional deficiencies studied.

The results shown above are great for the analysis of N, K and healthy plant deficiencies, obtaining very significant values for the evaluation of such problems, which are found in most Brazilian pastures.

It is necessary to increase the number of samples so that it is possible to improve learning and thus obtaining a more general $\mathrm{CNN}$, obtaining better results in the identification of deficiencies.

The confusion matrix (figures 7 and 8) shows that the deficiencies of Nitrogen and Potassium have similar characteristics, which leads the system to mix up such samples, so a larger number of images is necessary for the system to better learn these differences and achieve better generalization when each deficiency is presented to the system $[20,44]$.

Another value of having a data set with a larger number of images is that the influence of images that do not adequately present the characteristics of the analyzed anomalies will be weakened by the large number of adequate samples, increasing the reliability of the system [45].

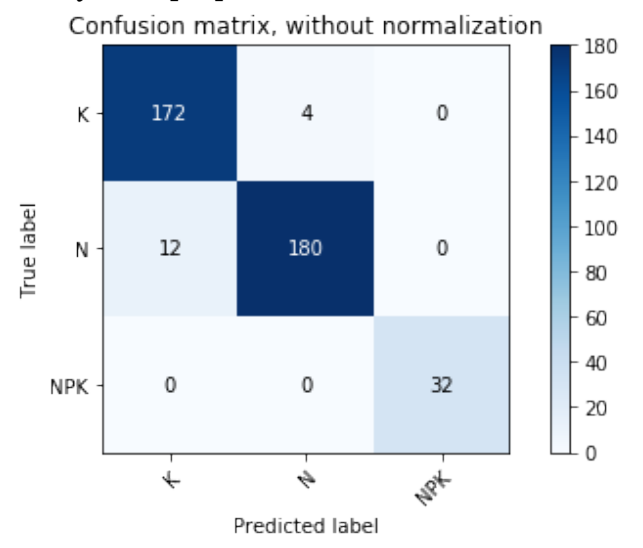

Figure 7 - Confusion matrix by the number of images.

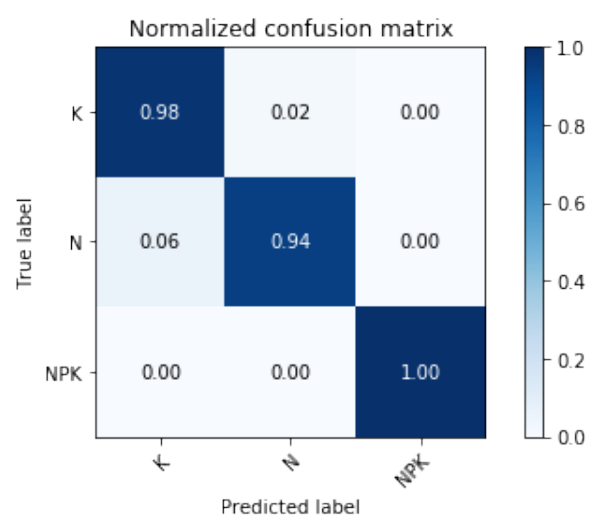

Figure 8 - Confusion matrix by the percentage of recognition. 
There are other metrics indicated in table 3, which can be used to assess the quality of our model, which are Precision and Recall, using Eq. (1), Eq. (2) [41].

$$
\begin{aligned}
& \text { Precision }[\%]=\frac{T P}{T P+F P} \times 100 \\
& \text { Recall }[\%]=\frac{T P}{T P+F N} \times 100
\end{aligned}
$$

Table 3 - Results using the Precision and Recall metrics in the test samples.

\begin{tabular}{llll}
\hline Nutrients & Precision & Recall & Samples \\
\hline Potassium & $93 \%$ & $98 \%$ & 176 \\
Nitrogen & $98 \%$ & $94 \%$ & 192 \\
Healthy & $100 \%$ & $100 \%$ & 32 \\
\hline Macro AVG & $97 \%$ & $97 \%$ & 400 \\
\hline
\end{tabular}

Precision is the ratio of true positives (TP) to the total sum of true positives (TP) and false positives (FP). Higher Precision indicates that the detector has identified fewer incorrect objects. The precision achieved was $93 \%$ for potassium, $98 \%$ for nitrogen and $100 \%$ for healthy plants, which shows that our system is very precise, having a lower value for nitrogen.

In the case of Recall we have $98 \%$ for potassium, $94 \%$ for nitrogen and $100 \%$ for healthy plants, which shows an excellent quality of classification for our model.

For the model to be considered efficient in addition to accuracy, we can assess the balance between Recall and Precision in each of the classes evaluated, our results show a balance between them and excellent levels of classification for both Recall and Precision.

This work was motivated by the lack of database and technologies applied to pastures in the Amazon region, more precisely in the state of Rondônia. In this region, the vast majority of livestock production uses pastures, with Brachiaria brizantha cv. marandu being one of the most important. Therefore, any increase in the quality of pastures will result in a greater quantity of animals per $\mathrm{m}^{2}$, increasing productivity per cultivated area and consequently demanding a smaller amount of area helping in environmental preservation. Studies show that in degraded pastures, productivity is around 2 arrobas/ha/year, while in pastures in good nutritional status it can reach an average of 16 arrobas/ha /year [1].

\section{Conclusion}

Deep learning is a recent technique for image processing and pattern recognition, it can effectively solve problems of pattern identification and recognition in images and identify nutritional problems in plants through the images of their leaves. The proposed model using CNN can effectively identify healthy plants, and plants deficient in nitrogen and potassium, using the images of their leaves. The system developed in this study achieved an overall accuracy of $96 \%, 97 \%$ of Precision and Recall, in detecting potassium and nitrogen deficiency and healthy plant using the test data set. This technology applied to pastures, with a great level of classification, like the one presented, demonstrates that it can help farmers improve their pastures, carrying out regular analyzes without the need for laboratory and specialist evaluation, which have high costs and demand time. Also, laboratory soil analysis are generally carried out at some points on the property, with the application of artificial intelligence technologies, it is possible to carry out the analyzes at as many points on the property as are necessary without significantly increasing costs.

The technology being developed is very important to meet the great demand of Brazilian pastures where only $20 \%$ are in excellent or good conditions, with $50 \%$ being heavily degraded, mainly in the North, Northeast and Midwest regions [2].

In the future, we intend to produce more samples of this pasture to increase the data set, creating samples both in the greenhouse and in the production environment. As a complementary action to this research, to be able to attend a greater number of cultivation areas, the creation of other data sets with other pastures used in the region is considered.

In addition to the production of new samples, we can use larger, pre-trained networks that could improve the system's classification levels, such as the use of VGG (16 and 19 layers), GoogleNet (22 layers) and ResNet (10 networks), 18, 32, 50 layers) [34,46-49]. 


\section{Acknowledgements}

This research is supported by Nvidia Corporation, which provided a Titan XP GPU for the development of the project.

The authors are grateful to CAPES for boosting technical knowledge through the postgraduate programs they administer.

\section{References}

[1] F. Alvim, B. Britaldo, S. Soares, F. Frank, D. Merry, H. De Oliveira, A. William, L. Souza, C. Michael, T. Coe, E. Lima, S. Batista, T. Gonçalves, M. Lilian, C. Sheepers, A. Ribeiro De Oliveira, H. Oliveira, R. Realização, Cenários para a pecuária de corte amazônica Autores, 2015. www.csr.ufmg.br (accessed September 9, 2019).

[2] M.B. Dias-filho, Diagnóstico das Pastagens, (2015). https://doi.org/10.13140/RG.2.1.4476.0169.

[3] E. Brasília, A. Hugo, Z. Manuel, C. Motta, M. Armindo, N. Kichel, R. Giolo De Almeida, Degradação, recuperação e renovação de pastagens, 2012. http://www.cnpgc.embrapa.br/publicacoes/doc/DOC189.pdf (accessed August 14, 2018).

[4] J.M.M. Taborda, Desenvolvimento da Pecuária Bovina no Estado de Rondônia: Contextualização Histórica e Indicadores Zootécnicos., Diss. (Mestrado Em Desenvolv. Reg. - Núcleo Ciências Exatas e Da Terra. (2015) 73.

[5] M.J. Alvim, M. de A. Botrel, D.F. Xavier, As principais espécies de Brachiaria utilizada no país., Comun. Técnico 22. (2002) 3-6.

[6] S. Bianco, M.A.R. Tonhão, R.A. Pitelli, Crescimento e nutrição mineral de capim-braquiária, Planta Daninha. 23 (2005) 423-428. https://doi.org/10.1590/S0100-83582005000300005.

[7] K.A. de P. Costa, I.P. de Oliveira, V. Faquin, Adubação Nitrogenada para Pastagens do Gênero, Doc. / Embrapa Arroz e Feijão. 1 (2006) 60.

[8] W. Marchesin, P. Henrique, D.C. Luz, V.R. Herling, Guia de identificação de deficiências nutricionais em Brachiaria brizantha cv. marandu., in: Comun. Técnico 76, 2007.

[9] V. Faquin, De Plantas No Agronegócio Diagnose Do Estado Nutricional Das Plantas, Ufla/Faepe. (2002) $1-75$.

[10] E. Malavolta, Elementos de nutrição mineral de plantas, São Paulo, SP, 1980.

[11] E. Malavolta, P.J. Romero, Manual de adubação, 2ed., São Paulo, 1975.

[12] E. Malavolta, Manual de nutrição mineral de plantas, São Paulo, SP, 2006.

[13] E. Malavolta, Manual de química agrícola, São Paulo, SP, 1976.

[14] J.. TOWNSEND, C.R.; COSTA, N. de L.; MENDES, A.M.; PEREIRA, R. de G.A.; MAGALHÃES, Nutrientes Limitantes em Solo de Pastagens Degradadas de Brachiaria Brizantha Cv. Marandu em Porto Velho-RO, Reun. Anu. Da Soc. Bras. Zootec. (2001).

[15] M.A. MARIN, Sistema de visão artificial para a diagnose nutricional de ferro , boro , zinco e cobre em plantas de milho Pirassununga-SP MÁRIO ANTONIO MARIN Sistema de visão artificial para a diagnose nutricional de ferro, boro, zinco e cobre em, 2012.

[16] Y. Lu, S. Yi, N. Zeng, Y. Liu, Y. Zhang, Identification of rice diseases using deep convolutional neural networks, Neurocomputing. 267 (2017) 378-384. https://doi.org/10.1016/J.NEUCOM.2017.06.023.

[17] J.G.A. Barbedo, Factors influencing the use of deep learning for plant disease recognition, Biosyst. Eng. 172 (2018) 84-91. https://doi.org/10.1016/J.BIOSYSTEMSENG.2018.05.013.

[18] I.N. da Silva, D. Spatti, R.A. Flausino, Redes neurais artificiais: para engenharia e ciências aplicadas, Artliber Editora Ltda, São Paulo, 2010.

[19] J. Amara, B. Bouaziz, A. Algergawy, A Deep Learning-based Approach for Banana Leaf Diseases Classification, Btw. (2017) 79-88. https://pdfs.semanticscholar.org/adae/9446cb66eaa6645dca78fd81b21d43aebdda.pdf (accessed June 24, 2019).

[20] J.G. Arnal Barbedo, Plant disease identification from individual lesions and spots using deep learning, Biosyst. Eng. 180 (2019) 96-107. https://doi.org/10.1016/J.BIOSYSTEMSENG.2019.02.002.

[21] J. Chen, Q. Liu, L. Gao, Visual tea leaf disease recognition using a convolutional neural network model, Symmetry (Basel). 11 (2019) 343. https://doi.org/10.3390/sym11030343.

[22] G. Geetharamani, A.P. J., Identification of plant leaf diseases using a nine-layer deep convolutional neural network, Comput. Electr. Eng. 76 (2019) 323-338. https://doi.org/10.1016/j.compeleceng.2019.04.011.

[23] J. Ma, K. Du, F. Zheng, L. Zhang, Z. Gong, Z. Sun, A recognition method for cucumber diseases using leaf 
symptom images based on deep convolutional neural network, Comput. Electron. Agric. 154 (2018) 18-24. https://doi.org/10.1016/j.compag.2018.08.048.

[24] P. Tm, A. Pranathi, K. Saiashritha, N.B. Chittaragi, S.G. Koolagudi, Tomato Leaf Disease Detection Using Convolutional Neural Networks, in: 2018 11th Int. Conf. Contemp. Comput. IC3 2018, Institute of Electrical and Electronics Engineers Inc., 2018. https://doi.org/10.1109/IC3.2018.8530532.

[25] S. Zhang, W. Huang, C. Zhang, Three-channel convolutional neural networks for vegetable leaf disease recognition, Cogn. Syst. Res. 53 (2019) 31-41. https://doi.org/10.1016/j.cogsys.2018.04.006.

[26] X. Zhang, Y. Qiao, F. Meng, C. Fan, M. Zhang, Identification of maize leaf diseases using improved deep convolutional neural networks, IEEE Access. 6 (2018) 30370-30377. https://doi.org/10.1109/ACCESS.2018.2844405.

[27] M. Kozłowski, P. Górecki, P.M. Szczypiński, Varietal classification of barley by convolutional neural networks, Biosyst. Eng. 184 (2019) 155-165. https://doi.org/10.1016/J.BIOSYSTEMSENG.2019.06.012.

[28] J. Grimm, K. Herzog, F. Rist, A. Kicherer, R. Töpfer, V. Steinhage, An adaptable approach to automated visual detection of plant organs with applications in grapevine breeding, Biosyst. Eng. 183 (2019) 170-183. https://doi.org/10.1016/J.BIOSYSTEMSENG.2019.04.018.

[29] J. Daniel López-Cabrera, L. Alberto López Rodriguez, M. Pérez-Díaz, Classification of breast cancer from digital mammography using deep learning, Intel. Artif. 23 (2020) 56-66. https://doi.org/10.4114/intartif.vol23iss65pp56-66.

[30] T.-T. Tran, J.-W. Choi, T.-T. Le, J.-W. Kim, T.-T. Tran, J.-W. Choi, T.-T.H. Le, J.-W. Kim, A Comparative Study of Deep CNN in Forecasting and Classifying the Macronutrient Deficiencies on Development of Tomato Plant, Appl. Sci. 9 (2019) 1601. https://doi.org/10.3390/app9081601.

[31] D. Casaroli, Q. de Jong van Lier, CRITÉRIOS PARA DETERMINAÇÃO DA CAPACIDADE DE VASO (1), 2008.

[32] Y. LeCun, Y. Bengio, G. Hinton, Deep learning, Nature. 521 (2015) 436-444. https://doi.org/10.1038/nature14539.

[33] S.P. Mohanty, D.P. Hughes, M. Salathé, Using Deep Learning for Image-Based Plant Disease Detection, Front. Plant Sci. 7 (2016) 1419. https://doi.org/10.3389/fpls.2016.01419.

[34] A. Kamilaris, F.X. Prenafeta-Boldú, Deep learning in agriculture: A survey, Comput. Electron. Agric. 147 (2018) 70-90. https://doi.org/10.1016/J.COMPAG.2018.02.016.

[35] M. Dyrmann, H. Karstoft, H.S. Midtiby, Plant species classification using deep convolutional neural network, Biosyst. Eng. 151 (2016) 72-80. https://doi.org/10.1016/J.BIOSYSTEMSENG.2016.08.024.

[36] Y. Sun, S. Zhu, X. Yang, M.V. Weston, K. Wang, Z. Shen, H. Xu, L. Chen, Nitrogen diagnosis based on dynamic characteristics of rice leaf image., PLoS One. 13 (2018) e0196298. https://doi.org/10.1371/journal.pone.0196298.

[37] S.-H. Wang, C. Tang, J. Sun, J. Yang, C. Huang, P. Phillips, Y.-D. Zhang, Multiple Sclerosis Identification by 14-Layer Convolutional Neural Network With Batch Normalization, Dropout, and Stochastic Pooling, Front. Neurosci. 12 (2018) 818. https://doi.org/10.3389/fnins.2018.00818.

[38] X. Zhu, M. Zhu, H. Ren, ScienceDirect Method of plant leaf recognition based on improved deep convolutional neural network Action editor: Ali Minai, Cogn. Syst. Res. 52 (2018) 223-233. https://doi.org/10.1016/j.cogsys.2018.06.008.

[39] C. Wick, F. Puppe, Leaf Identification Using a Deep Convolutional Neural Network, n.d. https://arxiv.org/pdf/1712.00967.pdf (accessed February 6, 2019).

[40] Y. Toda, F. Okura, How Convolutional Neural Networks Diagnose Plant Disease, Plant Phenomics. 2019 (2019) 1-14. https://doi.org/10.34133/2019/9237136.

[41] C. Account, A. Sharma, Convolutional Neural Networks with TensorFlow, Packt Publishing, 2018.

[42] S. Sladojevic, M. Arsenovic, A. Anderla, D. Culibrk, D. Stefanovic, Deep Neural Networks Based Recognition of Plant Diseases by Leaf Image Classification., Comput. Intell. Neurosci. 2016 (2016) 3289801. https://doi.org/10.1155/2016/3289801.

[43] D.P. Kingma, J. Lei Ba, ADAM: A METHOD FOR STOCHASTIC OPTIMIZATION, n.d. https://arxiv.org/pdf/1412.6980v8.pdf (accessed July 19, 2019).

[44] H.K. Suh, J. IJsselmuiden, J.W. Hofstee, E.J. van Henten, Transfer learning for the classification of sugar beet and volunteer potato under field conditions, Biosyst. Eng. 174 (2018) 50-65. https://doi.org/10.1016/j.biosystemseng.2018.06.017.

[45] J.G.A. Barbedo, Detection of nutrition deficiencies in plants using proximal images and machine learning: A review, Comput. Electron. Agric. 162 (2019) 482-492. https://doi.org/10.1016/j.compag.2019.04.035.

[46] M. Dyrmann, H. Karstoft, H. Skov, ScienceDirect Plant species classification using deep convolutional neural network, Biosyst. Eng. 151 (2016) 72-80. https://doi.org/10.1016/j.biosystemseng.2016.08.024.

[47] Y. Lu, S. Yi, N. Zeng, Y. Liu, Y. Zhang, Identification of rice diseases using deep convolutional neural 
networks, Neurocomputing. 267 (2017) 378-384. https://doi.org/10.1016/j.neucom.2017.06.023.

[48] S. Ghosal, D. Blystone, A.K. Singh, B. Ganapathysubramanian, A. Singh, S. Sarkar, An explainable deep machine vision framework for plant stress phenotyping., Proc. Natl. Acad. Sci. U. S. A. 115 (2018) $4613-$ 4618. https://doi.org/10.1073/pnas.1716999115.

[49] T.-T. Tran, J.-W. Choi, T.-T. Le, J.-W. Kim, T.-T. Tran, J.-W. Choi, T.-T.H. Le, J.-W. Kim, A Comparative Study of Deep CNN in Forecasting and Classifying the Macronutrient Deficiencies on Development of Tomato Plant, Appl. Sci. 9 (2019) 1601. https://doi.org/10.3390/app9081601. 